\title{
The posterior operation in treatment of cervical spondylosis with myelopathy: a long-term follow-up study
}

\author{
S. N. BISHARA ${ }^{1}$ \\ From the Department of Neurosurgery, The London Hospital, Whitechapel, London
}

SUMMARY An analytical study of 59 patients who underwent the posterior operation for cervical spondylosis with myelopathy at the London Hospital between 1945 and 1960 has been made. The postoperative period of observation ranged from five to 20 years with an average of 10 years. Initially 36 patients were improved by the operation, 24 considerably so, and in 15 patients further deterioration was prevented. Five years after operation 33 patients were still improved and in five patients co-existent disease had become apparent. Ten years after operation 30 patients had maintained their initial improvement; progression of the disease accounted for a drop of $10 \%$ in the success rate initially achieved. No patient in this series developed postoperative instability of the cervical spine. Patients with less than two years' duration of symptoms and with less neurological disability fared better. The importance of a long follow-up period for the proper assessment of results is thus emphasized. It is suggested that the posterior operation has stood the test of time and will continue to maintain a useful place in the treatment of this condition. Some points are outlined for the successful practice of this operation.

The first recorded reference to tetraplegia after an injury to the cervical spine is found in the Edwin Smith Papyrus (Breasted, 1930) written 4,000 years ago. It was not until 1892 that the first successful operation was done by Sir Victor Horsley on a 20-year-old builder with tetraplegia, two months after falling off his van. Horsley performed a laminectomy of the sixth cervical vertebra and found that 'a transverse ridge of bone projected backwards from the body of the vertebra and pressed upon the cord'. Eight months later, the patient was able to walk (Wilkinson, 1967).

The first complete delineation of the neurological syndrome of cervical spondylosis with myelopathy was made by Brain, Northfield, and Wilkinson (1952). They reported on 21 cases treated by laminectomy at the London Hospital. In 1955 Northfield reported on 39 patients who had laminectomy for cervical spondylosis with myelopathy. One patient who initially benefited from the operation deteriorated after nine years and had a more extensive

1Present address: Department of Neurosurgery, Dunedin Hospital and University of Otago Medical School, P.O. Box 946, Dunedin, New Zealand. laminectomy. Northfield drew attention to the lack of knowledge of whether improvement after operation would continue to be maintained.

This paper is based on the clinical study of 59 patients operated upon between 1945 and the end of 1960 in the London Hospital. These were followed up for more than five years after operation to assess the long-term result of posterior operation in the treatment of cervical spondylosis with myelopathy. The study includes the patients reported on by Northfield (1955).

\section{PATIENTS}

Fifty-nine patients who underwent a laminectomy for cervical spondylosis with myelopathy at the London Hospital between 1945 and 1960 were available for follow-up study for periods of five years or more. In 36 patients who were improved by the operation, the average follow-up period was 10 years with a range of five to 20 years. Seventeen patients were followed up for five to nine years, 13 for 10 to 14 years, and six for 15 to 20 years. The 23 patients who did not benefit from the operation were followed up for five to nine years.

All patients had neurological manifestations of damage to the cervical spinal cord which was believed to be due 
to spondylosis. All had some degree of weakness and spasticity of one or both lower limbs. At first the choice for operation was to some extent arbitrary. Later the criteria for operation became better defined: some patients were not subjected to operation because of age, diffuseness of the spondylosis, or vascular hypertension and atherosclerosis. Most of these patients were operated upon after failure of conservative treatment for a short period. Some, with a short history of progressive paraplegia, were subjected to operation without awaiting the effect of rest.

The investigations included plain radiographs (six views), lumbar puncture, and manometric studies with bilateral jugular compression with the head in the neutral position, extended and flexed, and full myelographic studies including views in extension and flexion.

The operation used was laminectomy. The technique was uniform throughout the period. The laminae related to the affected discs were removed including the one above and the one below together with the related ligamenta flava. The ligamenta denticulata were divided as far as could be reached in most cases; the dura mater was closed. If the intervertebral foramina were narrowed, they were unroofed by removing sufficient of the intervertebral facets. Only if there were extruded disc material was it removed; no attempt was made to remove the intervertebral bar except in very few cases early in the series. Delicacy and great care during induction of the anaesthetic, in placing the patient on and off the operating table, and in performing the operation were very strictly observed. After operation all patients were kept in bed for one week, and after extensive laminectomy skull traction callipers (10 lb., $4.5 \mathrm{~kg}$ ) were applied for two weeks. Thereafter every patient wore a collar, usually plastic, for three to 12 months according to the degree of spondylosis and the extent of operation (Northfield, 1955; Northfield and Osmond-Clarke, 1967).

\section{RESULTS}

This study was started with 69 patients. Three patients who improved considerably after the operation had to be excluded because they did not attain the minimal period of five years' follow-up after operation. Seven other patients died in less than five years after operation. Two died suddenly one week post-operatively and necropsy was refused. One patient who improved after operation died a month later, probably because of a pulmonary embolus. Four died two and a half years, three years, three years, and four years after operation from causes unrelated to their cervical disease. One had been improved by the operation, the other three had not.

In assessing the result of operation in the 59 patients available for the present study, the grading is arbitrary. No patient returned to complete normality. Patients who improved enough to return to their normal activities and normal earning capacity were considered considerably improved. This group includes a few who were left with very little disability indeed. Patients who improved but had $\underset{\mathbb{D}}{Z}$ residual disability enough to interfere with their earning capacity compared with that before theos onset of their disease were considered to be slightly improved. Then there were those patients who 0 remained stationary and those who slowly worsened.

In the first few months after operation 24 patients were considerably improved, 12 patients were $\stackrel{0}{=}$ slightly improved, 15 remained stationary, and.. eight slowly worsened-that is, in $61 \%$ an improve- $\overrightarrow{\vec{F}}$ ment was achieved by operation and in over $86 \%$ further deterioration appeared to have been prevented. In the improved group of 36 patients, $28 \frac{\bar{\omega}}{\mathrm{m}}$ were males and eight were females. In the unim- $\vec{\nabla}$ proved group of 23, 15 were males, and eight were $\varrho$ females.

The 36 improved patients ranged in age from 30 to $\overrightarrow{0}$ 77 years with an average age of 52 years. Twenty seven were in the 40 to 60 year age group. The $\vec{\omega}$ unimproved group of 23 ranged in age from $38 \stackrel{5}{-}$ to 65 years with an average age of 54 years. Thirteen were in the 40 to 60 year age group. It thus appears $\omega$ that in the present series age had no significant prognostic value.

The duration of symptoms in the improved grout from the first recognizable symptom to the time of 응 operation was from a few weeks to a few months i 18; a few months to two years in 11 and over tw years in seven-that is, in $80 \%$ of this group, the duration of symptoms was less than two years on In the unimproved group, five had symptoms for $\vec{\theta}$ few weeks to a few months before operation; s had the symptoms for a few months to two years and 12 had them for over two years. From this, it is clear that the duration of symptoms was longer in the unimproved group than in the improved group.

In Table 1 is set out an analysis of the abnormal neurological findings in the cases under review and $\bar{a}$ the correlation of their severity with the result of operation. From this analysis it is clear that the patients in the unimproved group were more disabled before operation than those in the improved group.

The extent of laminectomy, the number of $\bar{c}$ patients who had section of the dentate ligament, 3 and the number of patients who had foraminotomy $\delta$ in both groups of patients, the improved and the unimproved, is shown in Table 2.

From this analysis, it seems that when the number of discs affected is less-and hence the extent of laminectomy - the results are slightly better. Also, slightly more patients in whom dentate section was o done benefited from the operation than those in $N$ whom it was not used. But it seems that foraminotomy is better correlated with good results than 
TABLE 1

CORRELATION OF SEVERITY OF NEUROLOGICAL DISTURBANCE WITH RESULT OF OPERATION

\begin{tabular}{llcc}
\hline \multicolumn{2}{c}{ Neurological disturbance } & $\begin{array}{c}\text { Improved } \\
\text { group } \\
(36)\end{array}$ & $\begin{array}{c}\text { Unimproved } \\
\text { group } \\
(23)\end{array}$ \\
\hline $\begin{array}{l}\text { Upper limbs } \\
\text { Motor }\end{array}$ & Marked & 14 & 15 \\
& Slight & 19 & 8 \\
Absent & 3 & None \\
Sensory & Marked & 9 & 10 \\
& Slight & 12 & 5 \\
& Absent & 15 & 8 \\
Lower limbs & & & \\
Motor & Marked & 16 & 18 \\
& Slight & 20 & 5 \\
& Absent & None & None \\
Sensory & Marked & 8 & 12 \\
& Slight & 9 & 4 \\
& Absent & 19 & 7 \\
\hline
\end{tabular}

either the extent of laminectomy or dentate section. Partial laminectomy with attempt at disc removal was unsuccessful.

On reassessing the 59 patients five years after operation, it was found that the 24 patients who showed considerable initial improvement all maintained their improvement. One of them, a severely disabled 57 year old man (C.M.) who initially had three laminae removed, required a fusion operation 10 months later; he had slight subluxation which was originally underestimated. His subsequent course was excellent. Of the 12 patients who showed slight improvement to start with, three lost their gains, presumably due to progress of the disease, one (H.C.) after one year; the second (J.H.) after two years, and the third (A.R.) three years after operation. In three patients in whom there was no change after operation, the progress of the clinical

TABLE 2

CORRELATION OF SOME DETAILS OF OPERATIVE PROCEDURE WITH RESULT OF OPERATION

\begin{tabular}{lcc}
\hline Operative detail & $\begin{array}{c}\text { Improved } \\
\text { group } \\
(36)\end{array}$ & $\begin{array}{c}\text { Unimproved } \\
\text { group } \\
(23)\end{array}$ \\
\hline Laminae removed: & 15 & \\
2 & 11 & 8 \\
3 & 7 & 7 \\
4 & 1 & 3 \\
5 & 2 & None \\
Partial laminectomy and one disc & & 5 \\
removal & 27 & $(4$ had fusion) \\
Dentate section & 17 & 15 \\
Foraminotomy & & 5 \\
\hline
\end{tabular}

picture during the first five years of follow-up made it clear that they had disseminated sclerosis as well. In one of them the co-existence of this disease with the spondylotic myelopathy had been suspected before operation. In the other two it had not been suspected.

One patient (W.D.) who deteriorated progressively during the five years follow-up died 62 months after operation. Necropsy revealed, besides marked spondylosis, extensive sclerotic plaques in the brain and spinal cord. Another patient in the same group had a parasagittal meningioma removed eight months later.

After a 10 year follow-up, it became apparent that one patient (W.P.) who had been considerably improved by his operation, worsened slightly almost 10 years after the operation after a blow on the back of the head by a football. Five years later, there was further deterioration after he had twisted his neck suddenly when trying to avoid being struck by an object at work. A repeat myelogram at that time showed evidence of progression of the disease to involve the two discs below the one for which the laminectomy had been performed in 1949. However, lumbar CSF protein and lumbar manometric studies were normal. When last seen more than 16 years after his operation, he had moderate weakness of the right arm and distal weakness of the right leg with a slight right hemiparetic limp. He was still working as a painter.

Two patients who were slightly improved by operation had a setback. One (S.N.), nine years after operation, developed transient bizarre symptoms suggestive of vertebrobasilar insufficiency. However, as he had stopped working (railway clerk), he was considered to have worsened. The second patient (E.R.) had recurrence of symptoms eight years after her operation. A myelogram showed evidence of involvement of the disc below the one which had been decompressed by laminectomy eight years previously. Operative exploration was undertaken, but was complicated by severe haemorrhage and the operation had to be abandoned. Her condition continued to worsen and eight years later myelography was repeated. The findings were very similar to those disclosed eight years previously. However, there was no manometric block. Three years later, almost 19 years after her operation, she was no worse, but she was severely disabled.

The 30 patients who had maintained their improvement for 10 years after operation continued to be improved for longer periods of time. It will thus be seen that, in this series, whereas the percentage of improved patients shortly after operation was $61 \%$, this dropped to $51 \% 10$ years later due to progression of the disease (Table 3 ). 
TABLE 3

NUMBER OF PATIENTS IMPROVED SHORTLY AFTER OPERATION COMPARED WITH NUMBER 10 YEARS LATER

\begin{tabular}{cccccc}
\hline \multicolumn{2}{c}{ Shortly after operation } & & \multicolumn{2}{c}{ Ten years after operation } \\
\cline { 1 - 2 } \cline { 5 - 6 } $\begin{array}{c}\text { Considerably } \\
\text { improved }\end{array}$ & $\begin{array}{c}\text { Slightly } \\
\text { improved }\end{array}$ & & $\begin{array}{c}\text { Considerably } \\
\text { improved }\end{array}$ & $\begin{array}{c}\text { Slightly } \\
\text { improved }\end{array}$ \\
\hline 24 & 12 & & 23 & 7 \\
\hline
\end{tabular}

No patient in this series developed an instability of the cervical spine as a direct result of the laminectomy with or without foraminotomy. In the one case of fusion referred to above, instability and subluxation were present before the laminectomy and this may have aggravated it.

\section{DISCUSSION}

It is understandable that in a disease in which the pathogenesis and natural history are still debatable and the diagnosis is sometimes marred by uncertainty, the treatment remains controversial.

Ideally, if the myelopathy were a progressive disorder due solely to a continuous compression of the cervical cord by osteophytes and ligamentum flavum, operative removal of the compressing agents would have invariably provided excellent results. Such an operation would be comparable with the removal of a cord tumour. When cervical spondylosis was first recognized as a cause of myelopathy, it appeared to fall into the category of extramedullary compression of the spinal cord calling for laminectomy. Allen (1952) removed the protrusions extradurally through a laminectomy in 19 patients who were followed up for up to 27 months. The results were said to be satisfactory but no figures were given. However, this operation had to be abandoned because of the frequent disastrous results (Brain et al., 1952; Northfield, 1955, 1967; O'Connell, 1956; Rogers, 1961). From this evolved the posterior approach ranging from laminectomies with and without dentate section to extensive laminectomies and foraminotomies. Basically, the operation is a palliative measure providing a decompression of the cervical cord where the canal is believed to be narrowed and of the nerve roots lying in stenosed foramina. The different variants of the operation are usually undertaken in the belief that they will allow the cord to retreat backwards away from the ridges and that they will decompress the vessels supplying the cord. Disappointments are to be expected, as Northfield stated in 1955 , because the degree of compression is unmeasurable and perhaps in many the damage to the cord is to a greater or lesser extent ischaemic, and sustained before opera- $\overline{\mathbb{Q}}$ tion. Haft and Shenkin (1963) reviewed the literature and found that in 13 reported series, including their own, 303 patients were operated upon by the pose terior approach. Excellent and good results were $D$ obtained in $126(42 \%)$, fair in $79(26 \%)$, and poor in 98 (32\%). Northfield (1967) found that in $10 \stackrel{\text {. }}{\text {. }}$. series, including his own, 277 patients were operated upon by laminectomy for the relief of myelopathy. In some, the dura mater was left oren and in some $\overrightarrow{\vec{F}}$ the ligamenta denticulata were divided.Improvement occurred in $156(56 \%)$ patients, $70(25 \%)$ were un- $\frac{\bar{O}}{0}$ changed, and $51(19 \%)$ were made worse. Stoops and $\bar{\omega}$ King (1965) reported 42 patients for whom they $\widetilde{\Phi}$ performed extensive laminectomy with faraminotomies without opening the dura mater. These were ${ }^{\infty}$ followed up for one to six years. They claimed that $\vec{O}$ $83.3 \%$ showed definite improvement. They were $\overrightarrow{ }$ unable to identify specific prognostic factors beyond the severity of the myelopathy and recommended early operation in progressive myelopathy. From? these reports on a substantial number of patients $\omega$ and from the present report on 59 patients, if appears that further deterioration has been preventegd $\omega$ in practically four out of five cases. This is a worth- $\omega$ while achievement (Northfield, 1967).

On the other hand, O'Connell (1956), Campbêt and Phillips (1960), and Lees and Turner (1963) were so disappointed by the results of the posteriore operation that they advised a most conservatien approach in patients with cervical spondyloticic $\overrightarrow{0}$ myelopathy. It is hard to believe, in the 23 patients in the present study who were all considerably disabled before operation by progressive disease and in whom surgery resulted in a dramatic improvement maintained for over 10 years, that this improvement could have occurred spontaneously or with conserva- $\frac{}{\circ}$ tive measures.

The anterior approach (Robinson and Smith, $\overrightarrow{0}$ 1955; Cloward, 1958) has been well publicized in 3 recent literature. Dereymaeker, Ghosez, and Henkes (1963) analysed two groups of patients with spondy-? lotic myelopathy operated upon by either the anterior approach or the posterior approach and followed up for two to six years. The preoperative disability and the myelographic findings were very similar in the two groups. Of 31 patients who underwent $\delta$ an anterior cervical fusion, 20 improved. Of 12 who had laminectomy with excision of the disc, four im- 윽 proved. Of 11 who were only decompressed, five improved. They concluded that the anterior ap- 을. proach was superior. They did not abandon laminectomy but reserved it for those patients with complete $\sigma$ myelographic block in whom it might be difficult $N$ to exclude a spinal tumour. Crandall and Batzdorf $\underset{\omega}{N}$ (1966) reported their results in 62 patients operated 
upon for spondylotic myelopathy and followed up for one to 10 years. They concluded that, in cases of major cord compression at one or two levels from a relatively large amount of fibrocartilage, the anterior approach was the best. When three or more levels were affected, the posterior approach was to be preferred. Mayfield (1966), comparing his experience and that of others with both approaches, reached the conclusion that substantial recovery could be expected after decompression by wide laminectomy and foraminotomy at multiple levels. He expressed concern at the risk of subluxation which complicated two cases of his and two cases sent to him from elsewhere. However, on reviewing the preoperative radiography in the four cases, he found that in all there was some subluxation which had been overlooked. Sugar (1966-1967) concluded that the anterior cervical fusion is a useful procedure but not a panacea. Northfield (1967) considered that the reason for the lack of uniformity in the published results of operative treatment for spondylotic myelopathy by the posterior approach was obscure, though he thought that it might possibly be due to selection of patients and that the effect of operative anterior interbody fusion cannot yet be assessed as the numbers and duration of observation are inadequate.

The duration of follow-up is important for the fair assessment of the effect of treatment in a disease which many authors believe to be progressive in nature; a disease where differential diagnosis is difficult and where comparison between the results achieved by different methods of treatment is almost invariably invalidated by the different standards of selection of patients. Northfield (1955), in a trial to give the posterior approach as fair an assessment as possible, expressed his anxiety about whether improvement after operation would continue to be maintained. Bradshaw (1957), in following up for two years 14 patients who improved after laminectomy, found that seven rapidly deteriorated six to 18 months after operation. In six the reason was not clear but was speculatively explained by the development of arachnoiditis, and in one it was subluxation. Campbell and Phillips (1960), who followed their cases for two to 10 years, found that two of the improved cases ceased to work due to progression of the disease four and five years after operation respectively. Of 53 cases with provisional diagnosis of spondylotic myelopathy supported by myelography, nine cases proved later to have intrinsic disease of spinal cord or brain.

The present series is believed to have provided the longest period of observation after operative treatment of spondylotic myelopathy in a substantial number of patients. On the basis of this study and review of recent literature, it is claimed that the posterior operation has stood the test of time long enough to assure it a satisfactory place in the treatment of cervical spondylotic myelopathy. This remains to be proven for the anterior operation.

There are two well-known objections to the posterior operation. The first is that this operation does not arrest the progress of the spondylotic process. Both operations are essentially palliative. The anterior operation may arrest the progress at the fused intervertebral level, but not in neighbouring discs. It is speculated that anterior fusion at one level may aggravate degenerative changes at other levels. The second objection is postoperative instability of the cervical spine. This is not borne out by the present study and, unless extensive foraminotomies are performed or subluxation was present before operation but was overlooked, this risk should be minimal.

To achieve good results from the posterior operation, the following suggestions emerge from this study:

1. Accurate clinical and radiological diagnosis is of the utmost importance. The not infrequent coexistence of an intrinsic myelopathy with radiological signs of spondylosis should be born in mind.

2. Patients for operation should be selected with care. Early operation after failure of adequate conservative treatment is to be preferred, and operation avoided in patients with a long duration of symptoms and severe neurological disability suggesting irreversible damage to the spinal cord. Age in itself does not seem to be of specifically significant prognostic value for the operation.

3. Great care should be taken during the induction of anaesthesia and in placing the patient on and off the operating table not to allow the head and neck to be hyperextended. Great delicacy in the performance of the operation cannot be overemphasized.

4. Failure to discover the multiplicity of protrusions may sometimes account for the failure of operation to benefit (Brain et al., 1952). The laminectomy must be adequate but not unnecessarily extensive.

5. The addition of foraminotomy to laminectomy where foramina are narrowed. The fear of subluxation seems to be exaggerated. If the preoperative radiology suggests the presence of subluxation, anterior fusion is the operation of choice.

Other details of the operative technique, such as section of the ligamenta denticulata, not opening the dura mater or leaving it open, do not seem to affect the result of the operation significantly. However, it is to be remembered that generalizations apply to only a limited extent to the individual patients. 
I am deeply indebted to Mr D. W. C. Northfield and the late $\mathrm{Mr} \mathrm{J}$. V. Crawford for their kind permission to study their case material. I am most grateful to $\mathrm{Mr}$ Northfield, who suggested this study, for his constructive criticism and for his unstinted encouragement.

\section{REFERENCES}

Allen, K. L. (1952). Neuropathies caused by bony spurs in the cervical spine with special reference to surgical treatment. J. Neurol. Neurosurg. Psychiat., 15, 20-36.

Bradshaw, P. (1957). Some aspects of cervical spondylosis. Quart.J. Med., 26, 177-208.

Brain, W. R., Northfield, D., and Wilkinson, M. (1952). Neurological manifestations of cervical spondylosis. Brain, 75, 187-225.

Breasted, J. H. (1930). The Edwin Smith Surgical Papyrus, Vol. 1. (Cases 31 and 33), pp. 323-332 and 337-342. University of Chicago Press: Chicago.

Campbell, A. M. G., and Phillips, D. G. (1960). Cervical disc lesions with neurological disorder. Differential diagnosis, treatment, and prognosis. Brit. med. J., 2, 481-485.

Cloward, R. B. (1958). The anterior approach for removal of ruptured cervical disks. J. Neurosurg., 15, 602-617.

Crandall, P. H., and Batzdorf, U. (1966). Cervical spondylotic myelopathy. J. Neurosurg., 25, 57-66.

Dereymaeker, A., Ghosez, J.-P., and Henkes, R. (1963). Le traitement chirurgical de la discopathie cervicale. Résultats comparés de l'abord posterieur (laminectomie) et de l'abord ventral (fusion corporéale), dans cinquantaine de cas personels. (In French.) Neuro-chirurgie, 9, 13-20.

Haft, H., and Shenkin, H. A. (1963). Surgical end results of cervical ridge and disc problems. J. Amer. med. Assn., 186, 312-315.

Lees, F., and Turner, J. W. A. (1963). Natural history and prognosis of cervical spondylosis. Brit. med. J., 2, 16071610.

Mayfield, F. H., (1966). Cervical spondylosis: a comoarison of the anterior and posterior approaches. Clinical Neuro- $\infty$ surgery, pp.181-188. Williams and Wilkins: Baltimore.

Northfield, D. W. C. (1955). Diagnosis and treatment of myelopathy due to cervical spondylosis. Brit. med. J., 2, 1474-1477.

Northfield, D. W. C., and Osmond-Clarke, H. (1967). $\Rightarrow$ Surgical treatment, in Cervical Spondylosis and other $\stackrel{\vec{D}}{+}$ Disorders of the Cervical Spine. Edited by W. R. Brain and 0 M. Wilkinson. Pp. 207-222. Heinemann: London.

O'Connell, J. E. A. (1955). Discussion on cervical spondy- $\frac{\bar{\sigma}}{\bar{\omega}}$ losis. Proc. roy. Soc. Med., 49, 202-208.

Robinson, R. A., and Smith, G. W. (1955). Anterolateral $\overparen{D}$ cervical disc removal and interbody fusion for cervical disc syndrome. (Abstract.) Bull. Johns. Hopk. Hosp., 96, ळ 223-224.

Rogers, L. (1961). The treatment of cervical spondylitic myelopathy by mobilisation of the cervical cord into an enlarged spinal canal. J. Neurosurg., 18, 490-492.

Stoops, W. L., and King, R. B. (1965). Chronic myelopathy associated with cervical spondylosis. Its response to laminectomy and foramenotomy. J. Amer. med. Assn., 192, 281-284.

Sugar, O. (Editor) (1966-1967). Year Book of Neurolog Psychiatry and Neurosurgery. Pp. 601-602. Year Bood $\omega$ Medical Publishers: Chicago.

Wilkinson, M. (1967). Historical introduction, in Cervica্ Spondylosis and other Disorders of the Cervical Sping. Edited by W. R. Brain and M. Wilkinson. Pp. 1-9. Heine mann: London. 